\title{
Prosthetic Therapy of the Lateral Facial Defect
}

\author{
Vojkan Lazić ${ }^{1}$, Igor Djordjević ${ }^{2}$ \\ 'Department of Maxillofacial Surgery, School of Dentistry, University of Belgrade, Belgrade, Serbia; \\ ${ }^{2}$ Department of Prosthodontics, School of Dentistry, University of Belgrade, Belgrade, Serbia
}

\begin{abstract}
SUMMARY
Introduction Facial defects may arise as a result of head and neck trauma or facial tumor ablation. Minor defects can be reconstructed surgically while large defects usually need combined surgical and prosthetic reconstruction. The aim of this study was to present the prosthetic reconstruction of the lateral facial defect using facial colored acrylic prosthesis. Case Report A male patient with a maxillary defect on the left side and a large lateral facial defect on the same side received an obturator prosthesis as well as a facial colored acrylic prosthesis (facial-orbit) retained by the glasses frame. Satisfied aesthetics was accomplished. However, the stability of the prostheses during mandibular movements could not be achieved which resulted in saliva leakage over the lips.

Conclusion Better functional and aesthetic outcome could be achieved by combined surgical and prosthetic treatment of such large facial defect.
\end{abstract}

Keywords: acrylics; facial defects; obturator prosthesis; facial prosthesis

\section{INTRODUCTION}

Facial defects may arise as a result of head and neck trauma or as a result of facial tumor ablation (squamous cell and basal cell carcinomas). The corresponding defects may be smaller or larger depending on the size of the tumor or trauma. Minor defects are reconstructed surgically while large defects have to be reconstructed by combined, surgical and prosthetic intervention. One of main indications for prosthetic reconstruction are defects exposed to large doses of radiation (60 Gy or more), or when recurrent disease is expected [1]. Surgical reconstruction may be limited by the amount of the remaining bone and soft tissue and their quality, local vascular supply and need to periodically monitor the defect $[1,2]$. Prosthetic reconstruction is however limited by the presence of movable tissue and great difficulty of prosthesis retention in lateral facial defects. Prosthetic reconstruction should be performed when the tissue in the defect is healed and when the volume of the defect becomes stable after tumor ablation [1]. Facial prostheses are made of colored methyl methacrylate or silicone RTV (Room Temperature Vulcanization Silicone) [3]. Retention is carried by the glasses frame for acrylic facial prosthesis whereas silicone prosthesis can be retained by special glue for skin or craniofacial implants [1]. Reconstruction procedure should be planned together with a maxillofacial surgeon prior to surgery. The treatment plan should be presented to the patient and all advantages and disadvantages of facial reconstruction should be explained. Patients usually have too realistic expectations in terms of functionality and aesthetics [4].
The aim of this study was to present the prosthetic reconstruction of facial lateral defect by colored acrylic facial prosthesis.

\section{CASE REPORT}

A male patient with left maxillary defect and a large lateral facial defect on the same side appeared at the Department of Maxillofacial Surgery, School of Dentistry in Belgrade. After histopathological confirmation of malignant tumor in the region of maxillar paranasal cavity on the left side and precise localization of the tumor by computed tomography and magnetic resonance imaging (MRI), radical resection of the left maxillary bone with orbital exenteration and removal of soft tissue of the left cheek was performed (Figure 1). After completing radiotherapy, there was a six months waiting period before the facial reconstruction was done.

Definitive obturator prosthesis was made for the patient in order to facilitate chewing, swallowing and speaking. Physiological occlusal vertical dimension was also achieved by obturator prosthesis to maintain stable relationship of lower facial third and medial facial mass, very important for the reconstruction of lateral facial defects. Facial defect impression was taken by elastomers and alginate in combination with gypsum base as impression tray. A model was made of hard plaster and the prosthesis was shaped while the patient was sitting in front of a therapist. Firstly, the eyeball was centered in colored acrylic similar to the color of normal eye in antero-posterior, cranio-caudal and latero-lateral direction [5].After eyelids modeling, 


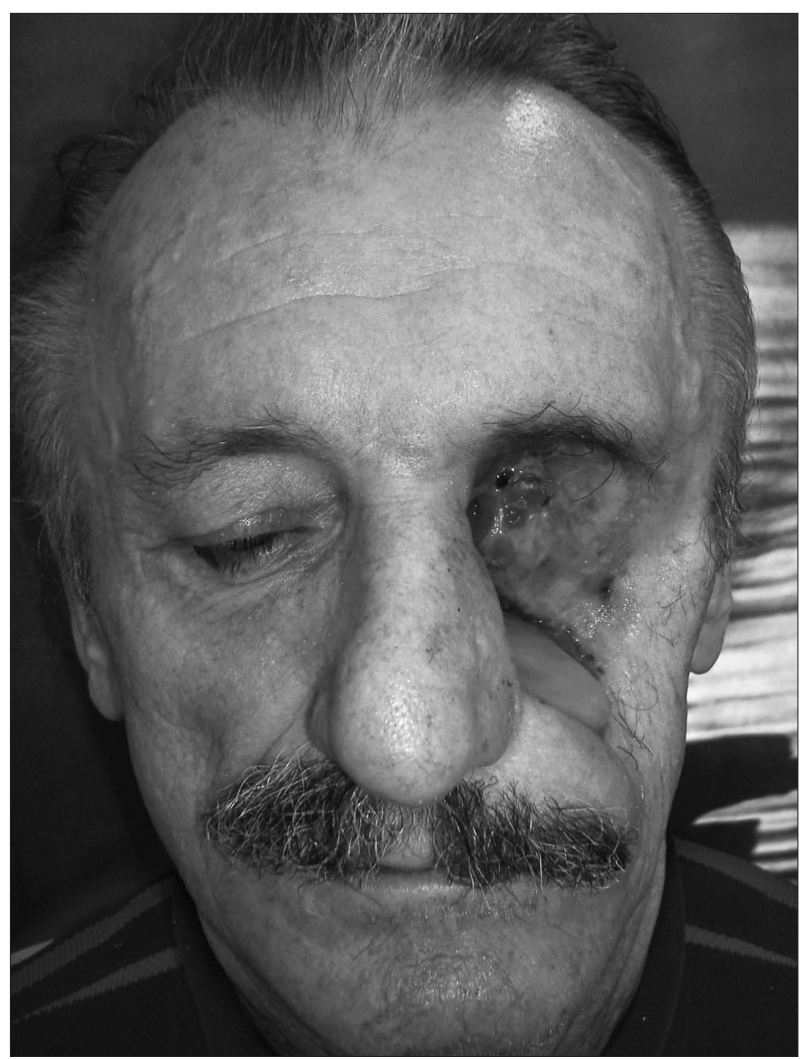

Figure 1. Lateral facial defect

Slika 1. Lateralni defekt lica

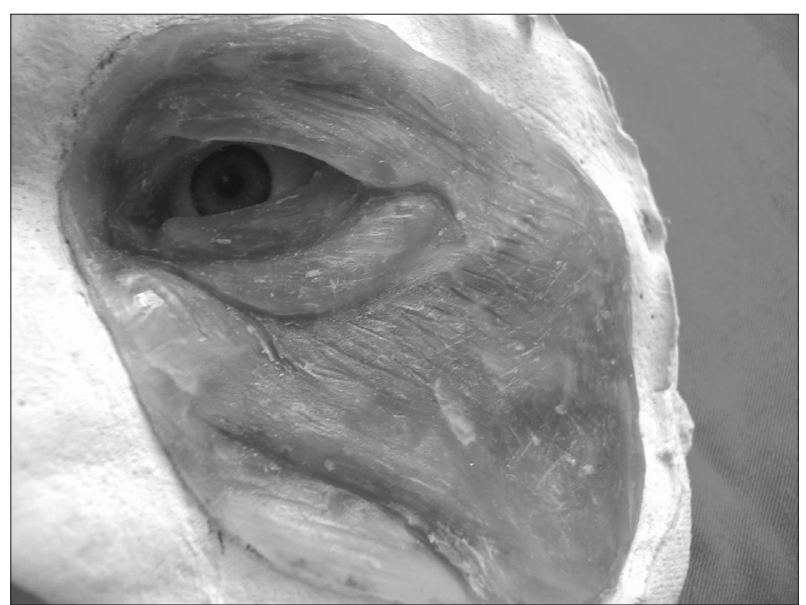

Figure 2. Wax model of facial prosthesis Slika 2. Voštani model proteze lica

zygomatic region and cheeks were shaped in wax. The size and the contour of future prosthesis depended on the size and direction of the defect. It was necessary to accentuate certain lines and individual facial characteristics on the wax model as well as the texture of the prosthesis in wax in order to have them better visible in acrylic after polymerization (Figure 2). Finished wax model of the facial prosthesis was tried on the patient (Figure 3) and after removal of excess wax from the basal part because of the reduction in weight of acrylic prosthesis, the model was sent for further processing.

Acrylic could be colored from the interior because of almost impossible exterior painting after the polymerisation. For interior coloring, oil colors, acrylic pigments and fibrics in various colors were used. During the prepara-

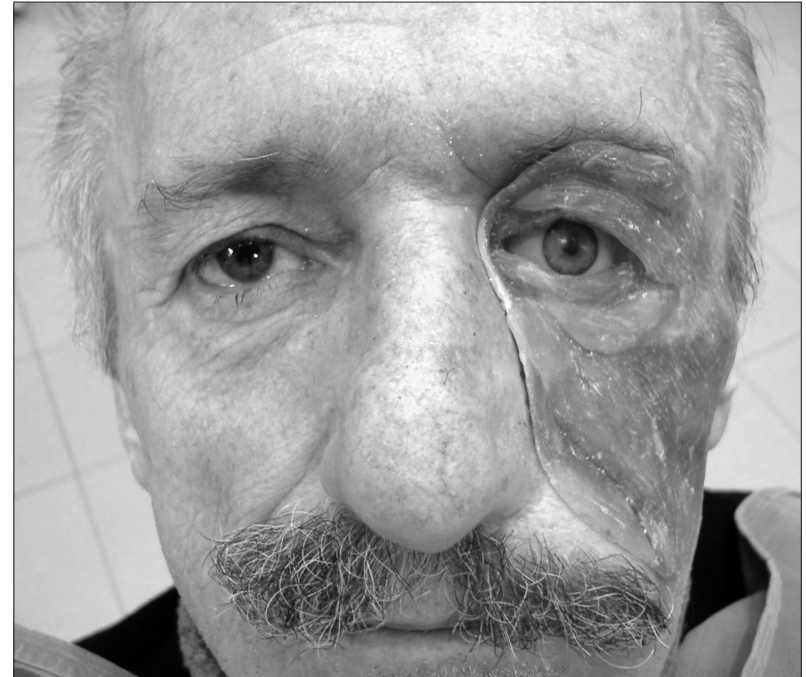

Figure 3. Wax model tried on the patient Slika 3. Proba voštanog modela na pacijentu

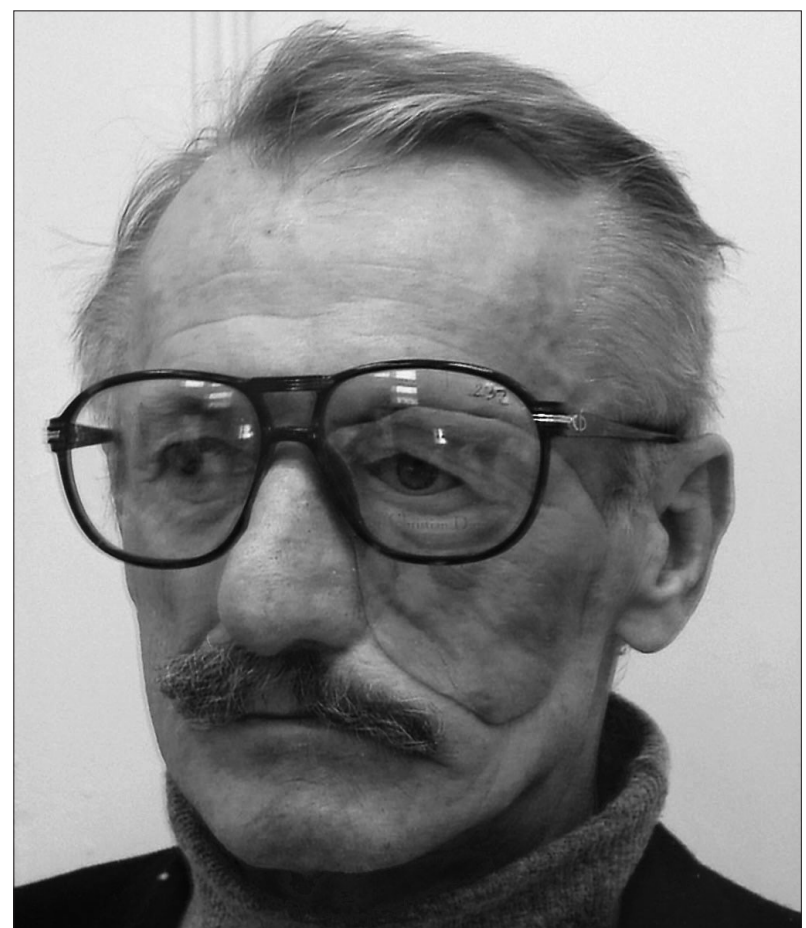

Figure 4. Final acrylic prosthesis in position retained on the glasses frame

Slika 4. Gotova akrilatna proteza lica retinirana preko okvira naočara

tion of colors, it was necessary to make several samples of acrylic in different shades in the skin color and to record a prescription with correct amounts and ratios of individual components [5]. After samples polymerization and comparison with the color of patient's face, one prescription was chosen. During acrylic polymerization base color was applied first after which acrylic in other colors was added for better aesthetics. A layer of cellophane was placed over the acrylic; the mold was sealed and placed under the press for a short time. After that, the mold was opened, the cellophane removed and the color checked before the final polymerization (colored mixture in the cuvette was compared to the patient's skin color). After the polymerization, the acrylic prosthesis was further processed, adapted if necessary, and attached to the glasses frame (Figure 4). 
Final reconstruction of the lateral facial defect by colored acrylic prosthesis was satisfactory, both aesthetically and functionally to some extent which was confirmed by the patient at regular checkups.

\section{DISCUSSION}

For the success of aesthetic facial prostheses, one of the most important things is well-designed surgical defect with minimal distortion of surrounding facial structures, if it was allowed by the size and the position of tumor. Lateral facial defects covered by skin graft are always desirable. These defects usually include moving tissues; therefore the prosthetic reconstruction is often inefficient and difficult to accept for most of patients. Facial prostheses can efficiently restore relatively fixed facial structures such as auricular, nasal, or upper lip prostheses. Defects occurred after the removal of maxilla and orbital exenteration that include a cheek region require surgical and prosthetic reconstruction, as suggested by Beumer et al. [1]. Prostheses can restore maxillary and orbital defects while the best way to restore cheek defect is by free micro vascular flaps taken from the forearm (radial flap) or other donor places [1]. It is not advisable to close maxillary and orbital defects by flap technique because it might affect the stability of obturator prostheses due to collected secretions from the nose and sinuses and consequent infection [1]. Usually, there is not enough room to place the eyeball and peri-bulbar tissue within the eye prosthesis if orbital defect was covered with the flap. Reconstructed cheek defect by free flaps provides support, stability and retention of maxillary obturator prosthesis while obturator prosthesis on the other hand provides cheek support and allows symmetry of the middle face. By obturator prosthesis, palatal contours are achieved as well as physiological anatomical position of the front and back teeth in order to establish optimal occlusion. After complete surgical - prosthetic rehabilitation, satisfactory cosmetic results can be achieved while the functions of speech, chewing and swallowing can be almost fully established [4].

The decision to reconstruct the lateral facial defect by prosthetic reconstruction only was made in this case because the patient refused to undergo additional surgery to close the cheek defect by skin graft. Craniofacial implants supraorbitally and laterally were suggested to the patient for better retention and stabilisation of large orbito-facial prosthesis. In that case, RTV silicone prosthesis with thin acrylic base could be built as suggested by Roumanas et al. [6]. That kind of prosthesis would be lighter, more aesthetic and would not move much during oral functions [1, 2]. That option was also rejected by the patient; therefore it was decided to reconstruct the lateral facial defect with acrylic prosthesis retained by the glasses frame. From the aesthetic point of view an optimal effect was achieved where patient could easily maintain hygiene of the defect and the prosthesis [4]. However, this prosthesis was big, heavy and inevitably affected movable cheek tissue. It was also very often dislocated by mandibular movements, speech or swallowing. In addition, oral competence could not be adequately reconstructed by acrylic prosthesis because the cheek defect in this patient was reaching the commissures. This conclusion is entirely consistent with the opinion of Beumer et al. [1]. The result of this reconstruction was inevitable saliva leakage during all mandibular movements regardless of the design and fitting of the prosthesis, which was also one of the disadvantages of this type of prosthetic reconstruction.

Satisfactory aesthetics was achieved by prosthetic reconstruction of the lateral facial defect with the colored acrylic prosthesis retained by the glasses frame, however good stability during mandibular movements could not be accomplished. Consequent leakage of saliva over the lips was also disadvantage of this prosthetic solution. Better functional and esthetic outcome could be achieved by surgical - prosthetic treatment of large facial defects.

\section{REFERENCES}

1. Beumer J, Curtis T, Marunick MT. Maxillofacial Rehabilitation, Prosthodontic and Surgical Considerations. St Louis, Tokyo: Ishiyaku EuroAmerica, Inc. Publishers; 1996.

2. Padmanabhan TV, Mohamed K, Parameswari D, Nitin SK. Prosthetic rehabilitation of an orbital and facial defect: a clinical report. J Prosthodont. 2012; 21:200-4.

3. Cantor R, Hildestad P. A material for epithesis. A preliminary report. Odont Tidskr. 1966; 74:32-40.

4. Chang TL, Garrett N, Roumanas E, Beumer J 3rd. Treatment satisfaction with facial prostheses. J Prosthet Dent. 2005; 94:275-80.

5. Dimitrijević B. Maksilofacijalne proteze i govor. Novi Sad: Dečje novine, Forum; 1984.

6. Roumanas ED, Chang TL, Beumer J. Use of osseointegrated implants in the restoration of head and neck defects. J Calif Dent Assoc. 2006; 34:711-8.

Received: 07/05/2012 • Accepted: 30/07/2012 


\title{
Protetička terapija lateralnog defekta lica
}

\author{
Vojkan Lazić', Igor Đorđević \\ ${ }^{1}$ Klinika za maksilofacijalnu hirurgiju, Stomatološki fakultet, Univerzitet u Beogradu, Beograd, Srbija; \\ ${ }^{2}$ Klinika za stomatološku protetiku, Stomatološki fakultet, Univerzitet u Beogradu, Beograd, Srbija
}

\begin{abstract}
KRATAK SADRŽAJ
Uvod Defekti lica mogu nastati kao posledica povrede glave i vrata ili usled ablacije tumora predela lica ili okoline. Manji defekti se rekonstruišu hirurški, dok se velika oštećenja uglavnom rekonstruišu kombinovano, primenom hirurških i protetičkih metoda. Cilj rada je bio da se prikaže protetička rekonstrukcija lateralnog defekta lica facijalnom protezom od akrilata u boji.

Prikaz bolesnika Muškarcu s defektom levog dela maksile i velikim lateralnim defektom lica s iste strane izrađene su opturator-proteza i proteza lica (orbito-facijalna) od akrilata u boji retiniranom preko okvira naočara. Time je postignut zadovoljavajući estetski izgled, ali nije postignuta stabilnost pri kretnjama mandibule, s posledičnim curenjem pljuvačke preko komisure usana.

Zaključak Bolji funkcionalni i estetski ishod bi se mogli postići hirurško-protetičkom terapijom ovako velikog defekta lica.
\end{abstract}

Ključne reči: akrilat; defekt lica; opturator-proteza; proteza lica

\section{UVOD}

Defekti lica mogu nastati kao posledica povrede glave i vrata ili usled ablacije tumora (planocelularni i bazocelularni karcinomi) predela lica ili okoline. Oni mogu biti mali ili veliki, u zavisnosti od stepena povrede ili veličine tumora. Manji defekti se rekonstruišu hirurški, dok se veća oštećenja uglavnom rekonstruišu primenom hirurškog i protetičkog pristupa. Jedan od glavnih razloga za protetičku rekonstrukciju jesu defekti izloženi velikoj dozi zračenja (60 Gy ili više) ili kada se očekuje recidiv oboljenja [1]. Hirurška rekonstrukcija može biti ograničena stanjem i količinom preostalog koštanog i mekog tkiva, stepenom oštećenja lokalne vaskularne mreže i potrebom da se periodično nadgleda onkološki defekt $[1,2]$. Protetička rekonstrukcija je, pak, ograničena postojanjem pokretnog tkiva i teškoćom retencije velikih proteza lica kod lateralnih oštećenja. Ona se vrši kada su oštećena tkiva zarasla i kada je veličina defekta ostala na istom nivou posle ablacije tumora [1]. Materijal od kojeg se izrađuju proteze lica je metil-metakrilat u boji ili RTV silikon (Room Temperature Vulcanization Silicone) u boji [3]. Retencija se vrši preko okvira naočara kod akrilatnih proteza lica, dok se proteze lica od silikona mogu pričvrstiti pomoću specijalnog lepka za kožu ili preko kraniofacijalnih implantata [1]. Način rekonstrukcije lica treba da se do detalja isplanira pre hirurškog zahvata zajedno s maksilofacijalnim hirurgom. Pacijentu se obavezno moraju predočiti plan terapije, prednosti i nedostaci rekonstrukcije lica posle povrede ili ablacije tumora. Obično u takvim situacijama pacijenti imaju suviše realistična očekivanja u pogledu funkcionalnosti i estetike [4].

Cilj ovog rada je bio da se prikaže protetička rekonstrukcija lateralnog defekta lica facijalnom protezom od akrilata u boji.

\section{PRIKAZ SLUČAJA}

Muškarac sa defektom levog dela maksile i velikim lateralnim defektom lica s iste strane javio se na Kliniku za maksilofacijalnu hirurgiju Stomatološkog fakulteta u Beogradu. S obzirom na histopatološki potvrđen nalaz malignog tumora u predelu gornjovilične šupljine s leve strane, kao i preciznog mesta tumora utvrđenog pomoću kompjuterizovane tomografije (CT) i nuklearne magnetne rezonancije (NMR), izvršena je radi- kalna resekcija levog dela maksile sa egzenteracijom orbite i uklanjanjem mekog tkiva obraza s leve strane (Slika 1). Posle primenjene zračne terapije čekalo se najmanje šest meseci na rekonstrukciju lica.

Najpre je izrađena konačna opturator-proteza, kako bi se pacijentu omogućili efikasno žvakanje, gutanje i govor. Ovom protezom takođe je postignuta fiziološka vertikalna dimenzija okluzije zbog održavanja stabilnog odnosa donje trećine lica i srednjeg facijalnog masiva, što je veoma važno kod rekonstrukcije lateralnih defekata lica protezama. Otisak defekta lica uzet je s elastomerima i alginatima u kombinaciji sa gipsanom osnovom kao kašikom. Mulaž je izrađen od tvrdog gipsa i na njemu je vršena modelacija epiteze u vosku za oblikovanje dok je pacijent sedeo ispred terapeuta. Najpre je izvršeno centriranje očne jabučice od akrilata u boji zdravog oka u antero-posteriornom, kranio-kaudalnom i latero-lateralnom pravcu [5]. Posle modelacije kapaka pristupilo se modelaciji zigomatične regije i obraza u vosku. Veličina i konture buduće proteze lica zavise od veličine i pravca pružanja defekta. Neophodno je naglasiti određene crte i individualne karakteristike lica na voštanom modelu, a naročito teksturu proteze u vosku, kako bi se bolje videle $\mathrm{u}$ akrilatu posle polimerizacije (Slika 2 ). Gotov voštani model facijalne proteze je potom konačno proban na pacijentu (Slika 3), te je nakon uklanjanja viška voska sa bazalne strane, zbog smanjenja težine u akrilatu, proteza poslata na kivetiranje.

Bojenje akrilata se može vršiti unutrašnjim bojenjem, jer je spoljašnje bojenje skoro nemoguće posle polimerizacije. Za unutrašnje bojenje se koriste uljane boje, akrilatni pigmenti i fibrice u raznim bojama. Tokom pripreme boje za protezu neophodno je izraditi najpre nekoliko različitih nijansi probnih pločica akrilata u boji kože pacijenta, s tim da se zabeleži recept s tačnom količinom i odnosom pojedinih komponenata [5]. Posle polimerizacije probnih pločica i poređenja s bojom lica donosi se odluka o tome koji će se recept koristiti u izradi akrilatne proteze lica. Pri kivetiranju se najpre nanosi smesa akrilata s osnovnom bojom, a onda se na željena mesta dodaju akrilatne smese druge boje radi postizanja efekta. Preko unesene smese bojenog akrilata u kivetu postavljen je sloj celofana; kiveta je zatim zatvorena i kratko stavljena pod presu. Potom je otvorena, uklonjen je celofan i urađena dodatna kontrola boje pre konačne polimerizacije (obojena smesa u kiveti poredi se s bojom kože pacijenta). Posle polimerizacije akrilatna proteza 
lica se obrađuje, po potrebi dodatno adaptira i vezuje na okvir naočara (Slika 4 ).

Rezultat rekonstrukcije lateralnog defekta lica akrilatnom protezom u boji bio je zadovoljavajući, kako estetski, tako i donekle funkcionalno, što je potvrdio i pacijent pri narednim kontrolnim pregledima.

\section{DISKUSIJA}

Osnova u izradi estetskih facijalnih proteza je dobro dizajniran hirurški defekt s minimalnom distorzijom okolnih facijalnih struktura, koliko to dozvoljavaju veličina i položaj tumora. Prekrivanje lateralnih facijalnih defekata slobodnim kožnim transplantatima je uvek poželjno. Ovi defekti sadrže dobrim delom pokretna tkiva, tako da je protetička rekonstrukcija često nedovoljno efikasna i teško prihvatljiva za većinu pacijenata. Protezama lica se veoma efikasno restauriraju strukture lica koje su relativno pokretne, kao što su aurikularne, nazalne ili proteze koje nadoknađuju gornju usnu. Oštećenja nastala posle maksilektomije i egzenteracije orbite, koja zadiru dobrim delom i u predeo obraza, obavezno se restauriraju hirurškim i protetičkim metodama, što naglašavaju Bojmer (Beumer) i saradnici [1]. Protezama se restauriraju defekti maksile i orbite, dok se oštećenja obraza najbolje restauriraju slobodnim mikrovaskularnim režnjem koji može da se uzme s podlaktice (radijalni režanj) ili drugih donorskih mesta [1]. Nije poželjno obliterisati maksilarne i orbitalne defekte tzv. flap tehnikom, jer se time ugrožava stabilnost opturator-proteza, a u usled sakupljanja sekreta iz nosa i sinusa može se razviti lokalna infekcija s pojavom fetora iz nosa [1]. Kod obliterisanih defekata orbite obično nema dovoljno mesta za postavljanje očne jabučice i peribulbarnih tkiva u okviru proteze oka, a posledično se javljaju i estetski problemi. Obraz rekonstruisan slobodnim mikrovaskularnim režnjem pruža potporu, stabilnost i retenciju maksilarne opturator-proteze dok opturacioni segment proteze, s druge strane, pruža potporu rekonstruisanom obrazu i omogućuje simetričnost srednjeg facijalnog masiva. Opturator-protezom se postižu konture palatuma i fiziološko anatomski položaj prednjih i bočnih zuba, kako bi se uspostavila optimalna okluzija. Posle kompletne hirurško-protetičke rehabilitacije mogu se postići zadovoljavajući estetski rezultati, dok se funkcije govora, žvakanja i gutanja skoro potpuno uspostavljaju [4].

Za razliku od hirurško-protetičke terapije, u ovom slučaju odlučeno je da se primeni isključivo protetička terapija lateralnog facijalnog defekta, zato što pacijent nije želeo da se podvrgne dodatnoj hirurškoj intervenciji zatvaranja oštećenja obraza slobodnom kožnim transplantatom. Pacijentu je predočena potreba ugradnje kraniofacijalnih implantata supraorbitalno i lateralno, da bi se velika orbito-facijalna proteza optimalno retinirala i stabilizovala. Tada bi mogla da se izradi proteza od RTV silikona s tankom akrilatnom podlogom, kako se navodi $\mathrm{u}$ istraživanju Rumanasa (Roumanas) i saradnika [6]. Takva proteza bi bila lakša i ne bi se mnogo pomerala tokom oralnih funkcija, a ostvario bi se i dobar estetski izgled $[1,2]$. Međutim, i tu opciju je pacijent odbio, tako da je odlučeno da se za rekonstrukciju lateralnog defekta lica uradi akrilna proteza u boji koju smo retinirali preko okvira naočara. S estetskog stanovišta, postignut je optimalni efekat koji je psihosocijalno prihvatljiv i pacijent je mogao veoma jednostavno da održava higijenu i defekta i proteze lica [4]. Međutim, ovakva proteza od akrilata u boji je velika, teška i neminovno zadire u pokretna tkiva obraza. Pri kretnjama mandibule, govoru ili gutanju često dolazi do dislokacije proteze. Osim toga oralna kompetencija nije mogla da se na odgovarajući način rekonstruiše akrilatnom protezom, jer je oštećenje obraza kod ovog pacijenta dopiralo do oralne komisure. Istog su mišljenja i Bojmer i saradnici [1]. Posledica toga je neminovno curenje pljuvačke pri svim kretnjama mandibule bez obzira na dizajn i naleganje proteze, što je takođe nedostatak ovog protetičkog rešenja.

Protetičkom rekonstrukcijom lateralnog facijalnog defekta protezom od akrilata u boji retiniranom preko okvira naočara postignut je zadovoljavajući estetski izgled, ali nije postignuta i stabilnost pri kretnjama mandibule. Posledično curenje pljuvačke preko komisure usana takođe je nedostatak ovakvog protetičkog rešenja. Bolji funkcionalni i estetski ishod se postiže kombinovanom hirurško-protetičkom terapijom velikih defekata lica. 